\title{
Establishing and Developing Professional Evaluator Dispositions
}

\author{
Randall S. Davies \\ Brigham Young University
}

\begin{abstract}
A basic principle associated with competent evaluation practice asserts that evaluators should possess the education, abilities, skills, and experience needed to undertake the tasks proposed in an evaluation. For those training evaluators this also means teaching professional dispositions, because an individual's dispositions (i.e., beliefs and values) influence how they will act as professionals. Personal dispositions held by individual evaluators at times conflict with the values and beliefs of their professional organization. Competent evaluators must be able to manage personal dispositions in ways that allow professional values and positions to guide their practice. In order for evaluation educators to teach evaluator competencies, we must understand the underlying dispositions associated with each competency. We must also identify which dispositions are essential for professional practice. This article discusses the issue of dispositions and the challenges of helping evaluators develop positive professional dispositions.
\end{abstract}

Keywords: evaluator training, evaluator competencies, professional dispositions

Résumé : Un principe de base associé à la pratique compétente de l'évaluation stipule que les évaluatrices et les évaluateurs devraient avoir la formation, les capacités et l'expérience nécessaires pour mener à bien les tâches d'une évaluation. Pour les personnes chargées de former des évaluatrices et des évaluateurs, cela signifie aussi enseigner des dispositions professionnelles, parce que les dispositions d'une personne (p. ex., ses croyances et ses valeurs) ont un effet sur son comportement professionnel. Les dispositions personnelles des évaluatrices et des évaluateurs peuvent parfois être en conflit avec les valeurs et les croyances de leur organisation professionnelle. Ces personnes doivent être en mesure de gérer leurs dispositions personnelles d'une manière qui permet aux valeurs et aux prises de position de leur profession d'orienter leur pratique. Afin d'enseigner les compétences d'évaluation, il est important de bien comprendre les dispositions sous-jacentes à chaque compétence. Il est aussi essentiel de reconnaître les dispositions qui sont essentielles à la pratique professionnelle. Le présent article discute de la question des dispositions et des défis liés au développement, par les évaluatrices et les évaluateurs, de dispositions professionnelles positives.

Mots clés : formation en évaluation, compétences en évaluation, dispositions professionnelles

Corresponding author: Randall Davies, Brigham Young University, 150L MCKB, Provo, UT, 84602; randy.davies@byu.edu 
Most evaluation organizations state in their codes of conduct, professional standards, guiding principles, and lists of evaluator competencies that evaluators should conduct evaluations in a competent manner (American Evaluation Association [AEA], 2018; AEA Evaluator Competencies Task Force, 2017; AES, 2013; AOTEROA, 2011; Canadian Evaluation Society [CES], 2018; UK Evaluation Society [UKES], 2013; United Nations Evaluation Group [UNEG], 2008; World Health Organization [WHO], 2013). The American Evaluation Association (AEA) asserts in its guiding principles that "evaluators should possess (or ensure that the evaluation team possesses) the education, abilities, skills, and experience appropriate to undertake the tasks proposed in the evaluation" (AEA, 2018). And like many evaluation organizations, the Australian Evaluation Society (AES, 2013) declares in its professional learning competency framework (AES-PLCF) that it is dedicated to providing education and training in all matters related to professional evaluation practice.

For the most part, evaluator competencies focus on the knowledge, skills, and abilities an individual might need in order to conduct a successful evaluation. However, the competencies identified by evaluation organizations worldwide are not solely skills- and knowledge-based; many are attitudinal dispositions and beliefs. The United Kingdom Evaluation Society (UKES, 2013), for example, includes in its evaluation capabilities framework (UKES-ECF) what it calls qualities and dispositions, referring to characteristics and attitudes that enable evaluators to function professionally. Likewise, the European Evaluation Society's (EES, 2015) evaluation capabilities framework (EES-ECF) lists specific dispositions and attitudes as essential competencies for professional evaluation practice. Those organizations that do not specifically use the term dispositions in their professional standards and evaluator competencies include expectations and competencies that are based on specific attitudinal dispositions.

Many evaluation educators have long believed that professional evaluators need professional dispositions (Gephart \& Ingle, 1977). Davidson (2004) suggested evaluators need to develop an evaluation attitude (see also Patton, 2008); she recommended that evaluation organizations should work toward defining the boundaries of evaluator education, setting criteria and standards, and conducting formative assessments of competencies, in an effort to help each evaluator improve their capabilities. This includes developing professional evaluator dispositions.

The purpose of this article is to explore the issue of professional evaluator dispositions. It articulates the importance of gaining consensus concerning essential dispositions, understanding which evaluator competencies might be considered dispositional, and distinguishing between personal and professional dispositions. Examples of how various organizations manage the issue of identifying essential dispositions, assessing dispositions, and regulating its members are provided. In addition, the challenges of training evaluators when the goal is to teach evaluator dispositions are discussed, as well as methods that evaluation educators might use for helping students develop professional dispositions. 


\section{DEFINING THE TERM DISPOSITION}

Words often have different meanings for different people. Academics are well known for using language that has specific meaning within their field but that is either poorly understood or used differently elsewhere. As the idea of a disposition is central to the discussion presented in this article, a working definition and explanation of the term are provided prior to discussing the importance of dispositions within the field of evaluation.

The dictionary definition of a disposition refers to inherent qualities of mind and character. A person's innate disposition can refer to one's predominant or typical mental and emotional temperament (e.g., a positive or happy disposition); however, in the context of evaluation and this article, dispositions refer to a person's state of mind, tendencies, and inclinations that affect the perspectives one has toward the practice of evaluation. These are attitudinal dispositions rather than innate personality traits.

Unlike knowledge, skills, and abilities, attitudinal dispositions describe an individual's values, beliefs, and opinions. Anderson and Bourke (2000) explained that affective characteristics like dispositions must involve feeling (typical and deeply held beliefs or attitudes), be targeted toward something (e.g., one's feelings about culture, ethics, or the purpose of evaluation), and vary in degree or magnitude for different individuals (i.e., the potential for individuals to have more or less positive or negative feelings about something).

Knowledge, skills, and ability typically fall in the cognitive domain. Dispositions, although in the affective domain, also have a conative component in that these personal characteristics are not only associated with feeling, beliefs, and opinions, but also involve free will and agency (Davies, 2009). While not dispositional in nature, many valued skills and abilities have dispositional aspects associated with their development and practice.

Fishbein and Ajzen's (1975) theory of reasoned action posits that attitudes toward social norms affect an individual's behaviour. According to the theory of planned behaviour, people typically align their behaviour with their personal belief systems, taking into account how they believe others would perceive their actions (Ajzen, 1991). Thus, the observed actions of professional evaluators are influenced by one's dispositions. Central to this concept is the recognition that an individual may be capable of performing specific skills and may understand important concepts but still choose to act in ways we might not expect due to his or her deeply held beliefs.

One criticism of accepting dispositions as a basis for professional competencies is the fear of indoctrination (Anderson \& Bourke, 2000)-forcing people to think a specific way against their will. Indoctrination is not inherently malicious. Although often associated with negative connotations, to indoctrinate originally meant to familiarize individuals with the doctrines (i.e., norms and values) of an institution or profession, with no implication that agreement with these norms and values would be forced. At issue is whose values and perspectives are being promoted and whether the associated dispositions are desirable and essential 
to evaluation practice. This becomes an issue when personal and professional dispositions differ.

Professional dispositions refer to attitudes and beliefs valued by a particular organization, as opposed to personal dispositions, which describe an individual's values, beliefs, and attitudes. An organization's code of conduct often maintains the stance that professionals in a field of endeavour are expected to manage personal dispositions in ways that allow professional values and positions to guide their behaviour (e.g., AEA, 2018). Foundational to this idea is the assertion that individuals have the right to form and hold their own values, beliefs, and opinions; but when one is employed in professional practice, one must conform behaviourally to the organization's beliefs and positions. It is therefore incumbent on professional organizations to carefully identify and articulate those attitudinal dispositions essential to professional practice.

\section{THE RELATIONSHIP BETWEEN DISPOSITIONS AND EVALUATOR COMPETENCIES}

While not always explicitly stated, many skills and abilities valued by evaluators have dispositional aspects associated with their development and practice. For example, the American Evaluation Association's (2018) evaluator competencies (AEA-EC) do not include the term dispositions; they frame the competencies as behaviours (e.g., the competent evaluator acts ethically). However, acting ethically is based on core values like trustworthiness, respect, fairness, caring, and doing what is right. For many competencies, the underlying disposition associated with a specific competency is clear, but not always. An associated dispositional stance may be widely accepted as an important professional expectation, or competent individuals within the field may fervently dispute the value and importance of the specific disposition and thus the competency. Exploring the relationship between specific competencies and their associated dispositions is important for evaluators in general, but particularly for those involved in evaluator training. To properly teach evaluator competencies, we must understand the nature of these competencies and the underlying dispositional assumptions and challenges associated with each. The following discussion of a few specific dispositions is provided to illustrate dispositional connections along with the challenges and issues associated with each.

\section{Ethics}

The most common expectation and competency found in every evaluation organization's list of competencies is that of ethical behaviour.

When considering this competency, evaluators seem to value the professional behaviour of acting and interacting ethically as essential to professional practice. On this point, the original competencies drafted by the AEA Evaluator Competencies Task Force (2017) included the expectation that evaluators act ethically in all five domains. Results of a survey designed to gauge the perspectives of AEA 
Table 1. Results from evaluator competencies survey regarding professional ethics

\begin{tabular}{lllllll}
\hline \multirow{2}{*}{ Domain } & \multirow{2}{*}{$\begin{array}{l}\text { Ethics } \\
\text { competency }\end{array}$} & \multicolumn{6}{l}{ Survey results regarding importance } \\
\cline { 3 - 7 } & & Extremely & Strongly & Moderately & Slightly & Not at all \\
\hline Professional & Act ethically & $85 \%$ & $13 \%$ & $2 \%$ & 0 & 0 \\
Methods & Act ethically & $88 \%$ & $10 \%$ & $1 \%$ & 0 & $1 \%$ \\
Context & Act and & $84 \%$ & $13 \%$ & $1 \%$ & 0 & $1 \%$ \\
Planning & $\begin{array}{c}\text { interact } \\
\text { Act ethically }\end{array}$ & $83 \%$ & $13 \%$ & $3 \%$ & 0 & $1 \%$ \\
Interpersonal & Act ethically & $84 \%$ & $12 \%$ & $3 \%$ & 0 & $1 \%$ \\
\hline
\end{tabular}

Note. Based on AEA Evaluator Competencies Task Force (2017); $N \approx 1215$.

members showed that $80-90 \%$ of respondents considered ethics important (see Table 1). Acting ethically was later removed from all but the professional practice domain as it was deemed sufficient to include it in the professional practice domain only; however, the results from the 2017 survey version affirm the declared importance of the expectation to evaluation professionals.

On the surface, ethics seems to be valued; however, these positive results might have been influenced by a social response set: Individuals are more likely to say something is important when they feel it would be politically incorrect to say otherwise. In addition, several respondents (approximately 48) considered ethics only moderately important or not important at all. In general, there is considerable agreement that acting ethically is an important expectation of professional evaluators, but not all agree. At least they do not all understand or value ethics the same (Morris, 2011). In fact, people from different countries and cultures often view ethical behavior very differently (Luegenbiehl \& Clancy, 2017). Acceptable behaviour in one location may be seen quite differently in another.

In practice, evaluators may indicate they believe acting ethically is important and still act unethically (Davies, 2009; Morris, 2009). In accounting, a specialized field of evaluation, the Chartered Institute of Management Accountants (CIMA, 2015) and the American Institute of Certified Public Accountants (AICPA, 2014) suggest that professional ethical behaviour involves integrity, objectivity, and compliance with accounting standards and principles, as well as discretion and confidentiality. This seems reasonable. However, these and other professional organizations realize they have a problem with unethical behaviour (Culiberg \& Mihelič, 2016; Henle et al., 2005), leading to calls for universities and training organizations to teach ethics (Aultman \& Whipkey, 2019; Bazerman \& Tenbrunsel, 2011).

For evaluator educators who attempt to teach ethics, it is easy to explain and test a student's understanding of ethical principles and professional codes of conduct but difficult to determine whether a student personally values these standards and will demonstrate moral and ethical behaviour when working unsupervised 
in the profession (Dutson et al., 1997). Not only does acting ethically require an understanding of what acting ethically means (Morris, 2011), professional behaviour is influenced by one's attitude toward the ethics expectation, as well as how strongly someone values acting ethically within specific situations and contexts.

\section{Cultural competence}

Another important attitudinal disposition entrenched in most sets of evaluator competencies is the expectation that evaluators understand, respect, and account for cultural aspects of any evaluation they conduct. In fact, the Aotearoa New Zealand Evaluation Association (ANZEA) competencies have been developed with an explicit focus on culture (Wehipeihana et al., 2014). They are ensconced within and informed by the Māori culture and traditions. Likewise, the AES-PLCF (AES, 2013) includes a domain focused on the attention to culture, stakeholders, and context. The UKES-ECF (UKES, 2013) and the EES-ECF (EES, 2015) expect evaluators to demonstrate cultural sensitivity and gender awareness.

The AEA-EC (AEA Evaluator Competencies Task Force, 2018) are based in the belief that professional evaluation practice should be grounded in the Program Evaluation Standards, the Guiding Principles for Evaluators, and the official documents of the organization. Thus, for the AEA, their statement on cultural competence frames an expectation of competent evaluation practice. Several times within various domains of the AEA-EC, specific competencies refer to culture (see Table 2). In each case, the underlying disposition related to the competency is implicitly stated within the AEA's statement on cultural competence.

Cultural competence is a disposition (AEA, 2011). It is a value-based perspective that many evaluation communities believe is worth nurturing. Being culturally competent indicates a positive dispositional stance toward the importance of culture. Being culturally competent involves an attitude toward culture that values diversity and respects the perspectives of those with different cultural experiences. To be culturally competent is not an attribute an evaluator obtains (like knowledge or skill); rather, it is a value the evaluator develops (Kirkhart, 2010). Demonstrating cultural competence requires more than knowledge and

Table 2. AEA evaluator competencies associated with the disposition of cultural competence

\begin{tabular}{ll}
\hline Domain & The competent evaluator \\
\hline $\begin{array}{c}\text { Professional } \\
\text { practice }\end{array}$ & 1.1 Respects people from different cultural backgrounds \\
Methodology & 2.10 Collects data using culturally appropriate procedures \\
Methodology & 2.11 Analyzes data using culturally appropriate procedures \\
$\begin{array}{l}\text { Context } \\
\text { Planning \& } \\
\quad \text { management }\end{array}$ & $\begin{array}{l}3.7 \text { Clarifies diverse perspectives ... and cultural assumptions } \\
\text { Interpersonal }\end{array}$ \\
\hline
\end{tabular}


awareness. It is demonstrated by the degree to which an individual accurately and respectfully represents diverse perspectives even when one disagrees, sometimes intensely, with the perspectives of others.

Certainly, not all evaluations have a cultural focus (in terms of race or ethnicity), and not all evaluators have a positive disposition toward culture and its importance. Still, competent evaluators do not disparage another's culture or try to change the deeply held beliefs of others to conform to the evaluator's beliefs and values. Having skill and knowledge (regardless of the strength of one's disposition) will influence the degree to which culturally appropriate procedures are effectively implemented; however, the degree to which one is willing to implement culturally appropriate procedures is determined by that person's attitude toward culture and the strength of the value she places on having a cultural focus in the evaluation. These dispositions are not learned; they are developed over time through dialogue, interaction, self-reflection and practice.

\section{The personal factor}

What Patton (2008) referred to as the personal factor is a disposition foundational for competencies involving evaluation use and capacity building (see Table 3 ). This disposition involves caring, interest, commitment, and enthusiasm for the evaluation process and the benefits of evaluation. Patton (2008) suggested that this disposition may be the most important explanatory variable in evaluation utilization. While most would agree that the personal factor is important, they may believe this for different reasons and to varying degrees. Some may advocate for evaluation use to ensure they will have work. On the other hand, they may believe that capacity building will threaten their job security. Others might value the evaluation process with a fervent belief that a properly conducted evaluation will contribute to improving individuals, organizations, and society. Still, many individuals complete evaluations and have evaluations completed for them without a positive attitude toward the benefits of evaluation. Like cultural competence, it is a belief that is developed over time.

\section{Interpersonal skills}

Many evaluator competency frameworks suggest the importance of evaluators having interpersonal skills. King and Stevahn (2013) asserted that anyone can develop good interpersonal skills and that the success of an evaluation is often determined by the evaluator's ability to manage the personal dynamics of

Table 3. AEA evaluator competencies associated with Patton's personal factor

\begin{tabular}{ll}
\hline Domain & The competent evaluator \\
\hline Professional practice & 1.9 Advocates for the field of evaluation and its value \\
Context & 3.8 Promotes evaluation use and influence in context \\
Planning \& management & 4.9 Works with stakeholders to build evaluation capacity \\
\hline
\end{tabular}


an evaluation; on this point, very few evaluation practitioners would disagree. Interpersonal skills, however, are not dispositions; they are not fundamentally affective. Interpersonal skills do, however, have a dispositional component. A positive disposition toward the value of participatory evaluation is foundational for competencies in the interpersonal domain. And while not all value or conduct participatory evaluations, an evaluator is more likely to develop and use their interpersonal skills if they have a strong belief that building relationships, managing conflicts, and understanding differing perspectives are important. In addition, developing a perspective of empathy toward those involved is cited as an important dispositional influence for interpersonal skill development (Johnson, 2018). So, while having or gaining the ability to properly manage the interpersonal dynamics of an evaluation is not a disposition, dispositions related to these skills can both facilitate their development and increase the likelihood that individuals will use them.

\section{CHALLENGES AND CONTROVERSIES WHEN IDENTIFYING ESSENTIAL DISPOSITIONS}

Developing professional dispositions is important. However, there are considerable obstacles involved with gaining consensus regarding which dispositions are and which are not essential to the practice of evaluation. For some dispositions there is a general consensus regarding their pertinence to evaluation and their value for professional practice; however, people do not all agree on the importance or acceptability of every disposition. The following examples are provided to illustrate specific challenges and issues associated with accepting various dispositions as essential to evaluation practice.

\section{Advocacy}

Within the professional practice domain of the AEA-EC is a statement that a competent evaluator identifies how evaluation practice can promote social justice and the public good. Most people would agree that advocating for social justice and the public good is admirable. At issue are whether advocacy is evaluation or pseudo-evaluation (Stufflebeam \& Coryn, 2014) and what constitutes promoting the public good (Patton, 1985; Schwandt, 2002). Social justice advocates are well represented in the AEA (Datta, 2002); however, the term social justice, like many evaluation terms, has variable meanings depending on who is using it and in what context it is being used. One common misconception is that social justice and cultural competence are the same. Some also incorrectly believe that there is one overriding value or belief regarding what constitutes being in the public's best interest (Schwandt, 2002). Evaluation societies are not the only organizations to struggle with this issue. The following example from the field of education is provided to illustrate how they have struggled identifying acceptable dispositions.

In 2000, the National Council for Accreditation of Teacher Education (NCATE) introduced new standards for accrediting college and university teacher 
preparation programs that included the concept of dispositions. The term disposition in this context was used to identify character traits, beliefs, and attitudes that teachers were expected to possess in order to be considered good teachers. NCATE incorporated the concept of dispositions with the expectation that a teacher's dispositions should be taught and measured, defining requisite dispositions as "beliefs and attitudes related to values such as caring, fairness, honesty, responsibility, and social justice" (NCATE, 2002, p.53). This definition met with considerable resistance, largely due to the inclusion of the words social justice (Alsup \& Miller, 2014; Powers, 2006).

In addition to the general concern that dispositions are difficult to teach and an individual's true dispositions are even more difficult to assess (Roberts, 2006; Shussler et al., 2005), critics articulated several potentially problematic issues regarding the expectation that teacher certification or school accreditation be based on whether individuals have a specific disposition (Alsup \& Miller, 2014; Powers, 2006). While most teachers agreed that certain professional dispositions would be acceptable, many took issue with including any disposition based on personal values or morals. They expressed concern over the likelihood that some dispositions have a variety of definitions and manifestations, often with ideological undertones. In addition, ethical and moral issues were raised regarding whether a teacher's certification should be withheld if he was perceived as not possessing the proper dispositions on specific social issues (Alsup \& Miller, 2014; McElroy, 2005; Powers, 2006; Will, 2006). Many felt that a "good teacher" could have specific opinions, beliefs, and values not aligned with those of other "good teachers." In response, NCATE clarified its position by removing the term social justice from its list of required teacher dispositions, focusing on the following:

Professional attitudes, values, and beliefs demonstrated through both verbal and non-verbal behaviors as educators interact with students, families, colleagues, and communities. These positive behaviors support student learning and development. NCATE expects institutions to assess professional dispositions based on observable behaviors in educational settings. The two professional dispositions that NCATE expects institutions to assess are fairness and the belief that all students can learn. Based on their mission and conceptual framework, professional education units can identify, define, and operationalize additional professional dispositions. (NCATE, 2008, p.89)

For many, this gesture represented an important line that needed to be drawn to ensure that institutionalization of a term would not lead to negative unintended consequences, as often occurs (Ravitch, 2004). Teachers and principals in US public schools are expected to understand the deeper norms and values that determine the culture of a school (Huff, 2012). They must understand how dispositions can shape the rituals, traditions, ceremonies, and celebrations that symbolize what is important, valued, and significant (Deal \& Peterson, 2009). However, for a teacher or principal to promote or advocate for a specific social agenda unrelated to the academic learning goals and objectives of the organization was seen as inappropriate in a public school. 
As a result of this rather contentious debate, NCATE retreated to a more politically safe delineation of dispositions, practices, and expectations for teachers that encompasses and espouses non-controversial aspects of social justice: caring and fairness. While not all agree (Alsup \& Miller, 2014), many teachers feel they have little influence on the root problems of social injustice in society; they are expected to work effectively with students of diverse backgrounds and socio-economic status toward clearly defined learning goals regardless of their personal beliefs on social issues. They feel their teaching should not be judged by their advocacy for or stances toward social justice issues. The current policy expects teachers to apply their knowledge, skills, and professional dispositions in a manner that facilitates student learning (NCATE, 2008).

This example is provided as an illustration of the controversial nature of some dispositions and the challenges that organizations face when attempting to identify essential dispositions pertinent to competent practice. With regards to promoting social justice and the public good, the ANZEA New Zealand evaluator competencies point out that no matter how well meaning or politically correct an evaluation might be, there will always be a tension between who is benefited from and who is marginalized by an evaluation (Wehipeihana et al., 2014). Two specific examples that demonstrate opposite positions on the appropriateness of advocacy in evaluation are the Chartered Institute of Management Accountants (CIMA, 2015) and the World Health Organisation (WHO, 2013). Each has a very different perspective on advocacy. CIMA views advocacy as an ethical threat; WHO sees it as an essential element to any evaluation. Both feel evaluators should be impartial and independent; however, while accountants view the evaluations they do as an objective task involving integrity and strict application of accounting principles and standards, WHO views advocacy for gender equity and human rights as crucial to almost all its health and development goals.

\section{Methods and evaluation purpose}

Disagreements regarding essential dispositions are not all based on social issues. Strongly held beliefs about evaluation approaches and methods have caused considerable controversy within evaluation (Alkin, 2012; Donaldson et al., 2014). While one of the expectations of professional evaluators is that we value diversity and respect others' opinions and perspectives, we do not always do it well. We often say that we should respect others' right to hold a divergent opinion, but too often we label emotionally charged opinions opposite to our own in a manner not so respectful nor accepting. In theory, we value diversity of thought and belief; in practice, we often encourage homogeneity of thought and values. We tend to believe there is a right way to think and act.

One particular disagreement among members of the AEA centered on what constitutes an appropriate evaluation design in situations where program effectiveness is central to the evaluation (Donaldson et al., 2014). Strongly held attitudes and opinions about best practice resulted in contentious debate. Wellarticulated arguments were presented for and against the US federal government's 
proposed priority for using scientifically based methods (i.e., random controlled trials or RCTs) when evaluating educational programs. The question of whether RCTs should be designated as the "gold standard" for determining causal effects was debated enthusiastically. The issue of causation, renamed by some evaluators as impact with attribution, was a central concern in the AEA's response to the proposed priority (AEA, 2003). In the end, the quant-qual wars subsided and a truce position endorsed the value of mixed methods. The third edition of the Joint Committee's Program Evaluation Standards combined statements from the previous edition about quantitative and qualitative designs into one unified standard, emphasizing the expectation for quality evaluations to employ technically adequate designs and analysis appropriate for an evaluation's purposes. A standard of reasoned justification was established rather than a methodological mandate.

This does not mean that an organization should never endorse a specific evaluation approach. For example, the World Health Organisation states in its evaluation guidelines that they value participatory approaches to evaluation that involve stakeholders at all levels (WHO, 2013). They belief that participatory evaluation approaches are best able to accomplish equity-focused evaluation. Recognizing the limitations of such approaches in terms of required resources, WHO suggests it may be necessary to balance the advantages of these approaches against resource availability. Given the organization's purpose and values, establishing a specific dispositional stance towards a specific evaluation approach might be reasonable for them, but not for all evaluators. Which dispositions are deemed essential is something each organization must establish for itself.

\section{DEVELOPMENT OF DISPOSITIONS}

Personal dispositions emerge naturally as the result of one's natural inclinations and exposure to applicable situations (Sasaki \& Kim, 2017). Helping individuals develop positive professional dispositions is attempted in a variety of formal settings (LaVelle \& Donaldson, 2015), but the pedagogy for teaching essential evaluator dispositions is considerably different from that used to teaching knowledge, skills, and abilities (LaVelle et al., 2020).

The goal of teaching students to value, appreciate, or develop a specific disposition can be a challenge. A prerequisite to teaching dispositions is coming to some agreement regarding which dispositions are and which are not essential to professional practice. Additionally, those who would teach professional dispositions must recognize that the notion that a disposition can be taught is likely an incorrect perspective. Dispositions are not taught; an individual develops her own beliefs, values, and opinions. The likelihood that an individual will develop a certain disposition can be enhanced through instruction and discussion, but individuals will determine for themselves what they believe and why that belief is or is not important. Attempting to persuade an individual that a specific disposition is needed does not guarantee that he will value that perspective. Dispositions develop over a lifetime and typically change by degree as an individual 
gains experience and better understands the issues and consequences of acting a certain way.

There are several approaches that might be taken when attempting to help evaluators develop dispositions. One framework that describes the process and contributes to understanding dispositions is Bloom's (1969) taxonomy for the affective domain (Krathwohl et al., 1964). This hierarchy describes five phases: receiving, responding, valuing, organizing, and internalizing. Receiving, responding, and organizing might best be described as process phases. Students are taught what the disposition is, they come to understand its particular components, and then they must resolve issues of practice. These phases are where instruction has the most influence. The valuing and internalizing phases could best be described as outcome phases. After learning about and reflecting on a specific disposition, students begin to value (or not value) that perspective. As individuals allow their developing dispositions to influence their behavior, they must resolve dissonance (e.g., practice vs. theory problems) to determine how they internalize the principle. Internalization shapes their decisions, affects their behaviour, and governs their actions; for evaluators this phase might affect the evaluation approaches they choose and the way they perform evaluation tasks.

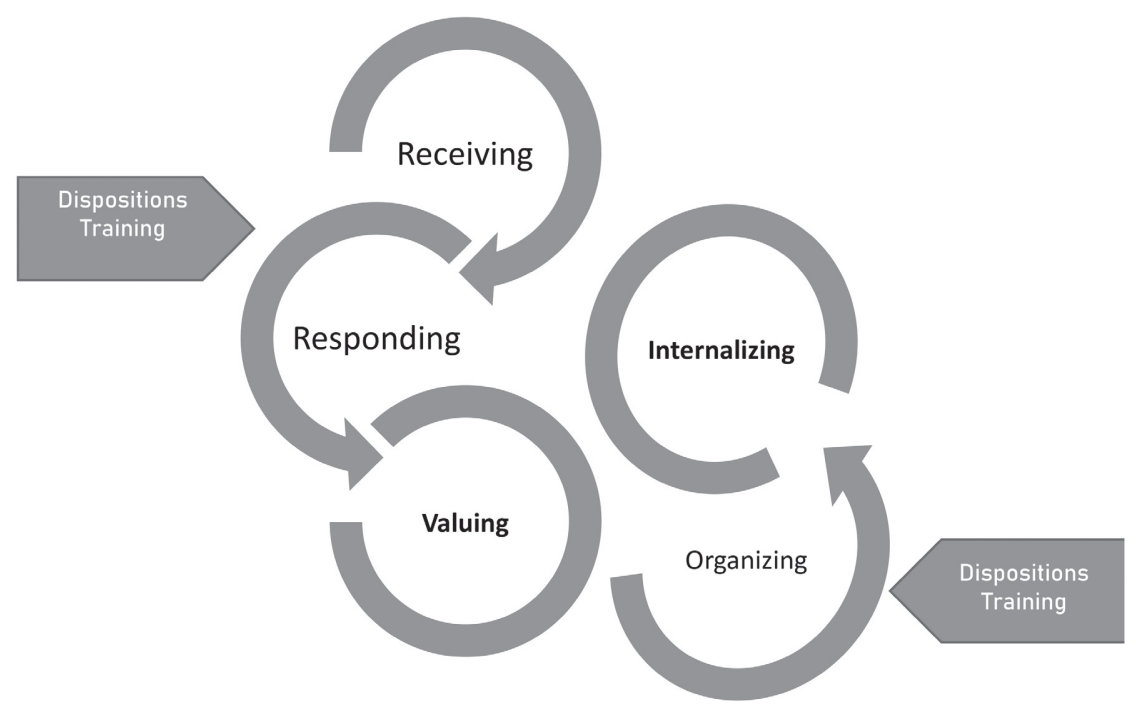

Figure 1. The cyclical process of Bloom's taxonomy for the affective domain. Bloom's taxonomy represents a cyclical process describing how dispositions are developed. It begins with receiving and responding, as students are provided explanations regarding what the disposition entails and are encouraged to ask questions about it. Within these phases, students are expected to gain a full understanding of the disposition. As a result of this process they will begin to form their beliefs and values. In the organizing phase, students will inevitably question the dispositions they hold as they attempt to resolve any dissonance they feel between what is expected of them and their personal beliefs and opinions. As they do this, their dispositions begin to take shape as an internalized way of being that guides actions and behaviours. 


\section{Receiving and responding phases}

In the first two phases of this process, instructors make students aware of standards and competencies expected of practicing professionals. Instruction helps students know and understand what the professional standards are on a cognitive level. Various techniques and pedagogies can be used to do this. During this phase the most important part of the instruction is to explain the underlying dispositions associated with the standards or competencies. Students are taught why the standards exist and why the profession considers them important. The goal of instruction is to influence students to develop a positive attitude toward the standards and competencies.

For example, instructors may teach student evaluators what cultural competence is and how vital it is to value diversity. They may give students a copy of AEA's Guiding Principles for Evaluators and stress the need for acting ethically. They should encourage students to ask questions about the standards and provide explanations to help them fully understand what is expected; students cannot gain an informed opinion about something if they do not have adequate information. However, understanding what is expected does not mean the students will consider all the standards important.

\section{Valuing phase}

Valuing is an outcome phase that does not involve instruction. After students have a basic understanding of a specific competency, they begin to form an opinion of its importance and value. A student may or may not have a positive disposition toward the standards or feel any strong need to develop specific competencies. To know what they will need or how they will act in specific situations, student evaluators may need more knowledge and experience (Johnson, 2018).

\section{Organizing phase}

Because personal dispositions are constantly being refined and developed, commonly an evaluator who understands the importance of a principle still acts contrary to it in specific situations. Perhaps the most important part of training evaluators is to help them resolve issues regarding inevitable dissonance between personal and professional standards (Morris, 2011). In the organizing phase, instructors must allow students to question a standard and explore the contextual aspects of an expectation. Instruction for this phase may take various forms, including role play, situation analysis, case studies, and reflection of practices. In many ways the students must be challenged to explore their true feelings and attitudes in light of the profession's behavioural expectations.

In this phase instructors must be careful to avoid attempting to change students' personal values and beliefs to conform with their own personal values or those of others in the profession. Instructors should emphasize understanding the standards and dispositions deemed essential for professional practice. For example, the Council on Social Work Education has identified 10 core competencies of 
social work practice (Council on Social Work [CSWE], 2018). These competencies include the expectation that those who identify as professional social workers will conduct themselves according to the standards of the National Association of Social Workers Code of Ethics. Along with these core competencies comes the expectation that individuals recognize and manage personal values in ways that allow professional values to guide their practice. Thus professional ethics related to the principles of conduct are determined by the profession, not the individual.

Ethical dilemmas can involve situations where the decision on how to proceed or act is complicated by differences between one's personal belief systems and the expected code of conduct. An individual behaves ethically in a profession by conforming to the accepted standards of the professional. So when the standard for social workers expects professional demeanour, not only in behaviour and communication but also in appearance, individuals are expected to defer to what the profession considers appropriate dress (appearance), not what the individual feels is appropriate. In professions like the American Nursing Association, the code of ethics is very precise regarding expectations for professional conduct. Many of these professions have a review of conduct procedure along with mechanisms for censuring those in the profession.

Considering social work, nursing, and evaluation, evaluation is the only one of the three that does not require a license to practice. But in each it is (or should be) acknowledged that individuals can act professionally and still have personal values or beliefs that do not align fully with the professionally approved dispositions and standards.

\section{Internalizing phase}

Like the value phase, internalizing is an outcome; but it may not be the final outcome. What we believe can change and often does over time. What we hope is that individuals will align their personal dispositions with those deemed important by the profession.

\section{ASSESSMENT OF DISPOSITIONS}

Assessing professional dispositions is challenging. A common criticism of the intended learning objectives adopted for many training programs is that they often focus (intentionally or otherwise) on lower-level learning objectives (remembering and understanding) or basic skill development. Assessed objectives typically ignore higher-level learning and affective learning objectives (Davies, 2009). Recognizing this weakness, the Accreditation Board for Engineering and Technology (ABET) established an expectation that engineering programs focus on 11 intentionally vague training goals based on Bloom's (1969) taxonomy for the cognitive domain, adding an objective from the affective domain: valuation (Shuman et al., 2005). This addition expresses the expectation that students value, appreciate, or develop specific attitudinal dispositions. This expectation comes with specific challenges. 
For example, expecting a student to appreciate and value the need to be a lifelong learner may be a worthy endeavour, but assessing this is a formidable challenge. Students may be able to articulate the arguments for such an attitude (knowledge and understanding), but educators may find it challenging if not impossible to determine how strongly a student holds a specific opinion (disposition or valuation).

Not all professions attempt to measure dispositions. For example, neither social work nor nursing attempts to assess the dispositions of their professionals (CSWE, 2018; National League for Nursing [NLN], 2008), being satisfied in knowing that those who work in the profession act in accordance with the profession's code of conduct regardless of their personal views and beliefs (NLN, 2008). Those professions that do expect dispositions to be taught and assessed (e.g., education and engineering) have no way to measure dispositions in a valid or reliable manner. Dispositions are often difficult to define and poorly understood, and rarely do all experts agree on their importance. Obtaining an accurate assessment of an individual's dispositions requires indirect measures using self-report or observations taken in an authentic situation over an extended period of time (Davies, 2009). These factors make it difficult to measure dispositions.

Because of the challenges involved with assessing dispositions, it may not be incumbent upon those training evaluators or for the profession in general to attempt this assessment. But even if we cannot measure one's dispositions well, it is important that educators attempt to help students develop desirable dispositions essential to professional evaluation practice.

\section{DISCUSSION AND CONCLUSIONS}

Because dispositions influence how evaluators act as professionals (Ajzen, 1991; Anderson \& Bourke, 2000; Fishbein \& Ajzen, 1975), it is important for evaluation organizations to identify which dispositions are essential for professional practice. Given the diverse opinions of evaluators and ways evaluation is practiced, this can be a daunting challenge. For evaluator educators, it is also important to understand the underlying dispositions associated with each of the evaluator competencies identified as essential for competent professional practice so they can decide how best to help students develop professional dispositions.

While it is difficult to judge the quality of an evaluation (Patton, 1990), it can be even more difficult to identify the degree to which an individual evaluator possesses all the abilities, skills, experience, and dispositions required to be considered a competent evaluator. And while training does not guarantee that an evaluator's work will be of high quality, the likelihood of avoiding mistakes will be increased with training and experience; this includes teaching new evaluators about professional standards as well as developing important evaluator dispositions.

Professional evaluators need professional dispositions (Gephart \& Ingle, 1977); however, evaluators need more consistent agreement about which dispositions are 
and which are not essential. Also, the profession needs to distinguish between professional dispositions and personal values, opinions, and beliefs. Ethical dilemmas occur when an individual's personal belief systems do not align with the profession's expected code of conduct. Ethical behaviour in the profession is confirmed when an individual conforms to accepted professional conduct standards regardless of their personal convictions. Issues arise when some in the profession insist that practitioners must hold dispositions that are not essential to competent practice. When no agreement can be reached regarding whether a specific disposition is essential, a compromise standard based on reasoned justification is often warranted.

For many licensed professions, those identified as professionals are expected to conduct themselves according to the standards of the profession regardless of their personal values and beliefs. These organizations (e.g., nursing and social work) typically identify mandatory behaviours based on clearly delineated procedures deemed appropriate by research conducted by experts in the field. These professions recognize that dispositions are difficult to teach and measure. They also realize that people typically align their behaviour with their personal belief systems (dispositions), but rather than attempting to change or measure personal beliefs, their training consists of explaining the desired professional behaviour and the consequences of not acting appropriately.

Some professions that expect those who are licensed to hold specific dispositions (e.g., education and engineering), although they cannot adequately assess dispositions, assume positive dispositions when observed behaviours (e.g., interactions with clients) align with established best practices toward clearly defined goals. Teacher training, for example, often involves teaching students expected behaviours (e.g., knowledge and understanding) but also attempting to persuade those entering the profession of the importance of holding specific dispositions (e.g., all student can learn) (NCATE, 2008). In licensed professions, censure is a possibility if an individual's behaviour is deemed inappropriate.

Those identifying themselves as evaluation professionals are not currently required to obtain a license or certification to practice. They conduct evaluations in many different contexts and for many different purposes. While a few dispositions are widely accepted as essential (e.g., Patton's personal factor-having a positive attitude toward the value of evaluation), far less agreement has supported other dispositions (e.g., valuing specific methods for determining the effectiveness of a program). Consequently, training novice evaluators involves more than teaching them what is expected and what consequences will occur if expectations are not met. Competent evaluators must be able to manage personal dispositions in ways that allow professional values to guide their practice.

There is no one correct way to train evaluators, as there is no single correct way to conduct an evaluation. However, understanding dispositions is important for those wishing to teach evaluator competencies. Understanding dispositions requires recognizing that skills and abilities are not dispositions; they are, however, founded in specific dispositions (i.e., values, beliefs, and opinions). Dispositions 
are not obtained by mastering a particular body of knowledge or set of skills. Teaching dispositions involves two important instructional steps: helping students fully understand what a disposition entails along with why the profession considers it important to competent practice, and allowing students to reflect on and resolve any dissonance they may feel between an expected professional disposition and their personal beliefs and opinions. Students must understand that the professional organization strongly advocates some dispositions and practices because they are deemed essential to competent professional practice. Other dispositions may be important and may guide professional practice but have not been recognized as essential to professional practice. Most important, when training evaluators, we must remember that we are not teaching students what to think. We are not imposing our values and beliefs on others. Following culturally competent best practices, we value differences of opinions; we attempt to fully understand and accurately and respectfully portray the diverse perspectives of others; and although we will do so imperfectly, we recognize that the importance of the endeavour is worth the effort.

\section{REFERENCES}

Ajzen, I. (1991). The theory of planned behaviour. Organizational behaviour and human decision processes, 50(2), 179-211. https://doi.org/10.1016/0749-5978(91)90020-t

Alkin, M. C. (2012). Evaluation roots: A wider perspective of theorists' views and influences. Sage.

Alsup, J., \& Miller, S. J. (2014). Reclaiming English education: Rooting social justice in dispositions. English Education, 46(3), 195-215.

American Evaluation Association. (2011). American Evaluation Association public statement on cultural competence in evaluation. https://www.eval.org $/ \mathrm{p} / \mathrm{cm} / \mathrm{ld} / \mathrm{fid}=92$

American Evaluation Association. (2013). American Evaluation Association response to U.S. Department of Education. http://www.eval.org/p/cm/ld/fid=95

American Evaluation Association. (2018). American evaluation association guiding principles for evaluators. https://www.eval.org/p/cm/ld/fid=51

American Evaluation Association Evaluator Competencies Task Force. (2017). Presenting the final draft of the AEA Evaluator Competencies. AEA conference presentation, Washington, DC.

American Evaluation Association Evaluator Competencies Task Force. (2018). The 2018 AEA evaluator competencies. https://www.eval.org/page/competencies

American Institute of Certified Public Accountants. (2014). AICPA code of professional conduct. https://pub.aicpa.org/codeofconduct/Ethics.aspx\#

Anderson, L. W., \& Bourke, S. F. (2000). Assessing affective characteristics in the schools (2nd ed). Lawrence Erlbaum Associates.

Aotearoa New Zealand Evaluation Association. (2011). Evaluator competencies. https:// www.anzea.org.nz/app/uploads/2019/04/ANZEA-Superu-Evaluation-standardsfinal-020415.pdf 
Aultman, J., \& Whipkey, A. J. (2019). Moving beyond moral revulsion: A deeper analysis of social justice within clinical ethics training. The American Journal of Bioethics, 19(4), 67-69. https://doi.org/10.1080/15265161.2019.1572821

Australasian Evaluation Society (AES). (2013). Evaluators' professional learning competency framework. Australasian Evaluation Society, Melbourne, Australia.

Bazerman, M. H., \& Tenbrunsel, A. E. (2011). Ethical breakdowns. Harvard Business Review, 89(4), 58-65.

Bloom, B. S. (1969). Taxonomy of educational objectives: The classification of educational goals. Handbook I. Cognitive Domain. McKay.

Canadian Evaluation Society. (2018). Competencies for Canadian evaluation practice. https://evaluationcanada.ca/competencies-canadian-evaluators

Chartered Institute of Management Accountants. (2015). CIMA code of ethics. https://www. cimaglobal.com/Professionalism/Ethics/CIMA-code-of-ethics-for-professionalaccountants/

Council on Social Work. (2018). Council on Social Work education core competency. https://www.cswe.org/getattachment/Accreditation/Accreditation-Process/2015EPAS/2015EPAS_Web_FINAL.pdf.aspx

Culiberg, B., \& Mihelič, K. K. (2016). Three ethical frames of reference: Insights into Millennials' ethical judgements and intentions in the workplace. Business Ethics: A European Review, 25(1), 94-111. https://doi.org/10.1111/beer.12106

Datta, L.-E. (2002). The case of the uncertain bridge. American Journal of Evaluation, 23, 187-206. https://doi.org/10.1177/109821400202300207

Davidson, E. J. (2004). Evaluation methodology basics: The nuts and bolts of sound evaluation. Sage.

Davies, R. S. (2009). Exploring the meaning and function of learner intent for students taking online university courses. VDM Publishing House.

Deal, T. E., \& Peterson, K. D. (2009). Shaping school culture: Pitfalls, paradoxes, and promises (2nd ed.). Jossey-Bass.

Donaldson, S. I., Christie, C. A., \& Mark, M. M. (2014). Credible and actionable evidence: The foundation for rigorous and influential evaluations. Sage.

Dutson, A. J., Todd, R. H., Magleby, S. P., \& Sorensen, C. D. (1997) A review of literature on teaching design through project-oriented capstone courses. Journal of Engineering Education, 76(1), 17-28. https://doi.org/10.1002/j.2168-9830.1997.tb00260.x

European Evaluation Society. (2015). The EES evaluation capabilities Framework. https:// europeanevaluation.org/wp-content/uploads/2020/03/EES-EVALUATION-CAP ABILITIES-FRAMEWORK.pdf

Fishbein, M., \& Ajzen, I. (1975). Belief, attitude, intention, and behaviour: An introduction to theory and research. Addison-Wesley.

Gephart, W. J., \& Ingle, R. B. (1977). The introductory evaluation course. NSPER: 77. https:// eric.ed.gov/?id=ED182347

Henle, C. A., Giacalone, R. A., \& Jurkiewicz, C. L. (2005). The role of ethical ideology in workplace deviance. Journal of Business Ethics, 56(3), 219-230. https://doi.org/10.1007/ s10551-004-2779-8 
Huff, S. B. (2012). Culture rules: This is the way we do it here. McKay School of Education College Honored Alumni Lecture, Brigham Young University.

Johnson, S. M. (2018). The development and use of interpersonal competencies by evaluators (Unpublished doctoral dissertation). University of Minnesota.

King, J. A., \& Stevahn, L. (2013). Interactive evaluation practice: Mastering the interpersonal dynamics of program evaluation. Sage.

Kirkhart, K. E. (2010). Eyes on the prize: Multicultural validity and evaluation theory. American Journal of Evaluation, 31(3), 400-413. https://doi.org/10.1177/1098214010373645

Krathwohl, D. R., Bloom, B. S., \& Masia, B. B. (1964). Taxonomy of educational objectives: Handbook II: Affective domain. David McKay Co.

LaVelle, J. M., \& Donaldson, S. I. (2015). The state of preparing evaluators. In J. W. Altschuld \& M. Engle (Eds.), Accreditation, certification, and credentialing: Relevant concerns for U.S. evaluators. New Directions for Evaluation, 145, 39-52. https://doi. org/10.1002/ev.20110

LaVelle, J. M., Lovato, C. Y., \& Stephenson C. L. (2020). Pedagogical considerations for the teaching of evaluation. Evaluation and Program Planning, 79. Article 101786. https:// doi.org/10.1016/j.evalprogplan.2020.101786

Luegenbiehl, H., \& Clancy, R. (2017). Global engineering ethics. Butterworth-Heinemann.

McElroy, W. (2005). Cultural competence: Coming to a school near you? https://www.lew rockwell.com/2005/10/wendy-mcelroy/cultural-competence-coming-to-a-schoolnearyou/

Morris, M. (2009). The fifth guiding principle: Beacon, banality, or Pandora's box? American Journal of Evaluation, 30(2), 220-224. https://doi.org/10.1177/1098214009334589

Morris, M. (2011). The good, the bad, and the evaluator: 25 years of AJE ethics. American Journal of Evaluation, 32(1), 134-151. https://doi.org/10.1177/1098214010388267

National Council for Accreditation of Teacher Education. (2002). Professional standards for the accreditation of schools, colleges, and departments of education. Author.

National Council for the Accreditation of Teacher Education. (2008).Professional Standards Accreditation of Teacher Preparation Institutions http://www.ncate.org/ /media/Files/ caep/accreditation-resources/ncate-standards-2008.pdf?la=en

National League for Nursing. (2008). Nurse educator core competency. http://www.nln.org/ professional-development-programs/competencies-for-nursing-education/nurseeducator-core-competency

Patton, M. Q. (1985). Cross-cultural nongeneralizations. In M. Q. Patton (Ed.), Culture and evaluation: New directions for program evaluation (vol. 25). Jossey-Bass.

Patton, M. Q. (1990). Qualitative evaluation and research methods. Sage.

Patton, M. Q. (2008). Utilization-focused evaluation (4th ed.). Sage.

Powers, E. (2006). A spirited disposition debate. Inside Higher Education. http://www. insidehighered.com/news/2006/06/06/disposition

Ravitch, D. (2004). The language police: How pressure groups restrict what students learn. Random House.

Roberts, R. (2006). Assessing teacher dispositions. Presentation at the annual meeting of the American Association of Colleges of Teacher Education, San Diego, CA. 
Sasaki, J. Y., \& Kim, H. S. (2017). Nature, nurture, and their interplay: A review of cultural neuroscience. Journal of Cross-Cultural Psychology, 48(1), 4-22. https://doi. org/10.1177/0022022116680481

Schwandt, T. A. (2002). Evaluation practice reconsidered. Peter Lang.

Shuman, L. J., Besterfield-Sacre, M., \& McGourty, J. (2005). The ABET “professional skills": Can they be taught? Can they be assessed? Journal of Engineering Education, 94(1), 41-55. https://doi.org/10.1002/j.2168-9830.2005.tb00828.x

Shussler, D., Stookberry, L., \& Bercaw, L. (2005). Conceptualizing dispositions: Intellectual, cultural, and moral domains of teaching. Paper presented at the annual meeting of the American Educational Research Association, Montreal, QC.

Stufflebeam, D. L., \& Coryn, C. L. S. (2014). Evaluation theory, models, and applications (2nd ed.). Jossey-Bass \& Pfeiffer Imprints, Wiley.

UK Evaluation Society. (2013). Framework of evaluation capabilities. https://www.evaluation. org.uk/app/uploads/2019/04/UK-Evaluation-Society-Framework-of-EvaluationCapabilities.pdf

United Nations Evaluation Group. (2008). Core competencies for evaluators of the UN system. http://www.uneval.org/document/detail/1408

Wehipeihana, N., Bailey, R., Davidson, E. J., \& McKegg, K. (2014). Evaluator competencies: The Aotearoa New Zealand experience. The Canadian Journal of Program Evaluation, 28(3), 49-69.

Will, G. (2006, January 16). Ed schools vs. education. Newsweek.

World Health Organization. (2013). WHO evaluation practice handbook. https://apps.who. int/iris/bitstream/10665/96311/1/9789241548687_eng.pdf

\section{AUTHOR INFORMATION}

Randall Davies is an associate professor of instructional psychology and technology at Brigham Young University. His research involves technology integration and educational program evaluation. His primary teaching responsibilities include program evaluation, educational assessment, and survey research. 